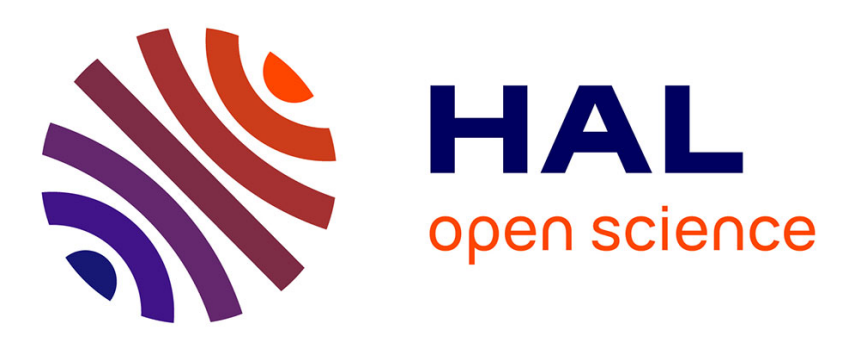

\title{
Toolbox of post-synthetic mordenite modification strategies: Impact on textural, acidic and catalytic properties
}

Hussein Issa, Nourrddine Chaouti, Joumana Toufaily, Tayssir Hamieh, Alexander Sachse, Ludovic Pinard

\section{To cite this version:}

Hussein Issa, Nourrddine Chaouti, Joumana Toufaily, Tayssir Hamieh, Alexander Sachse, et al.. Toolbox of post-synthetic mordenite modification strategies: Impact on textural, acidic and catalytic properties. ChemCatChem, 2019, 11 (18), pp.4581-4592. 10.1002/cctc.201900927 . hal-02359011

\section{HAL Id: hal-02359011 \\ https://hal.science/hal-02359011}

Submitted on 12 Nov 2019

HAL is a multi-disciplinary open access archive for the deposit and dissemination of scientific research documents, whether they are published or not. The documents may come from teaching and research institutions in France or abroad, or from public or private research centers.
L'archive ouverte pluridisciplinaire HAL, est destinée au dépôt et à la diffusion de documents scientifiques de niveau recherche, publiés ou non, émanant des établissements d'enseignement et de recherche français ou étrangers, des laboratoires publics ou privés. 


\title{
Toolbox of post-synthetic mordenite modification strategies: Impact on textural, acidic and catalytic properties
}

\author{
Hussein Issa ${ }^{[a]}$, Nourrddine Chaouti ${ }^{[a]}$, Joumana Toufaily ${ }^{[b]}$, Tayssir Hamieh ${ }^{[b]]}$, Alexander Sachse ${ }^{*[a]}$ \\ Ludovic Pinard ${ }^{\star[a]}$
}

\begin{abstract}
Which post-synthetic modification strategy is the best suited for the generation of particular textural or chemical features in mordenite for a desired catalytic application? The aim of this contribution is to shed light on the effective quality of zeolite hierarchization through the rational study of structure/catalytic property dependency. Our study focused on mordenite, as this zeolite is of particular importance due to its strong acidity and monodimensional channel system, which explains why mordenite is industrially extensively employed. A toolbox of post-synthetic hierarchization strategies on aluminium rich and poor mordenites has been developed based on basic treatments assisted by CTAB and pyridine at various temperatures (in conventional and microwave heating) and acid HF etching in aqueous and organic medium. A systematic study of over 30 post-synthetically modified mordenites was conducted, which allowed us to assess the impact of each hierarchization strategy on textural, morphological, chemical and catalytic properties. Major correlations between structural features and catalytic activity, selectivity and stability in both the monomolecular $n$-hexane cracking and the bimolecular toluene disproportionation were deduced.
\end{abstract}

\section{Introduction}

Mordenite is one of the zeolites that finds major use as heterogeneous catalyst in a number of processes in the petrochemical industry, such as the toluene disproportionation, alkylations and hydroisomerizations. ${ }^{[1]}$ This can be ascribed to the unique acidic and shape selective properties that mordenite features. Its framework is formed by the intergrowth of 5 -linked atoms laterally to form a three-dimensional network. This stack generates two one-dimensional porous systems in the [001] direction. The first in the form of channels with 12-MRs $(7.0 \times 6.5$ $\AA)$, which communicate with each other through apertures of 8MRs $(3.4 \times 4.8 \AA)$, these are also named side pockets. The second is a network of one-dimensional channels of 8-MRs (2.6 $x 5.7 \AA$ ), which are adjacent to the 12-MRs. As most molecules cannot enter the 8-MRs, mordenite is doomed to single file diffusion through the parallel $12-\mathrm{MRs}^{[2]}$ This structural

[a] Institut de Chimie des Milieux et Matériaux de Poitiers (IC2MP) UMR 7285 CNRS, UFR SFA, Bât. B27, 4 rue Michel Brunet, TSA 51106, 86073 Poitiers Cedex 9 (France)

ludovic.pinard@univ-poitiers.fr, alexander.sachse@univ-poitiers.fr

[b] Université Libanaise, Laboratoire des matériaux, catalyse, environnement et méthodes analytiques (MCEMA), Hadath, Liban

Supporting information for this article is given via a link at the end of the document characteristic renders mordenite extremely prone to rapid pore blocking and deactivation in catalytic processes. ${ }^{[3]}$

In order to realize the full potential of mordenite the development of secondary porosity within its structure has been put forward. ${ }^{[4]}$ This approach allows to reduce the diffusion path length (hence increase catalytic activity, selectivity and stability) and at the same time increase the accessibility of bulkier molecules to the active sites. ${ }^{[5-7]}$ In this quest, a multitude of strategies have been proposed with the aim at achieving mordenite featuring hierarchical porosity. ${ }^{[8]}$ Most of these strategies are related to post-synthetic modifications. For this purpose microporous mordenite is firstly synthesized and secondary porosity is introduced through a post-synthetic treatment step. Due to their simplicity and cost efficiency dealumination and desilication processes are the most prosperous strategies. The industrially applied steaming processes yield to dealuminated mordenites, which have proven to introduce secondary porosity to the systems. ${ }^{[1,9]}$ Dealumination has yet severe consequences related to the extraction of aluminium, which implies a direct loss of acidity. Though the formation of secondary porosity, Boveri et al. ${ }^{[10]}$ have indeed proven that the catalytic gain can be annihilated by the reduction of active sites.

Treatments with certain chemical agents, such as silicon tetrachloride $\left(\mathrm{SiCl}_{4}\right)$ and ammonium hexafluorosilicate (AHFS) can further lead to dealumination. A restricted number of studies have focused on the dealumination of mordenite with AHFS. ${ }^{[11]}$ The development of an aluminium gradient in the framework as a consequence of the AHFS treatment has been observed, indicating that the process is diffusion controlled. ${ }^{[12]}$ This observation has further been correlated to a deposit of silica ${ }^{[13]}$ accompanied by a slight reduction of the crystallinity and of the unit cell volume. ${ }^{[14]}$ The dealumination with a total amount of AHFS corresponding to $100 \%$ of total aluminium content of $\mathrm{H}$ MOR resulted in approximately $13 \%$ dealumination; while, it allowed for a dealumination of up to 24 and $50 \%$ for ZSM-5 and $\mathrm{Y}$, respectively. ${ }^{[13]}$

A further post-synthetic strategy is etching using aqueous HF solutions, which allows to extract selectively aluminium from the zeolite framework and hence decrease the Brønsted acidity with important consequences on the catalytic performance. ${ }^{[15]}$ Valtchev and co-workers designed an etching process which is based on altering the $\mathrm{HF}$ ionization equilibrium in water through the addition of $\mathrm{NH}_{4} \mathrm{~F}$ and which hence allows for the unbiased removal of $\mathrm{Si}$ and $\mathrm{Al}$ from the zeolite framework. ${ }^{[16]}$ In our previous study, we developed a new mordenite etching procedure, which relies on the use of a pyridinic HF solution. ${ }^{[17]}$ We observed that the HF etching in pyridine allows for the development of mordenite catalysts with superior catalytic properties.

The removal of silicon form the zeolite through alkaline treatment has proven very efficient for preserving acidic properties to a certain extend whilst allowing for the development of mesoporosity. ${ }^{[18]}$ The use of microwave heating 
during the alkaline treatment has been found to accelerate the generation of defined intracrystalline mesopores due to the more efficient transfer of thermal heat to the zeolite solution. ${ }^{[19,20]}$ The group of Ivanova substantially contributed to the understanding of the impact of surfactants during alkaline treatment of mordenite. Depending on the severity of the alkaline treatment various composite materials (mordenite/amorphous MCM-41 type phase featuring zeolite fragments in the pore walls) could be achieved $\left.{ }^{[21-23}\right]$ The obtained materials have been found to be catalytically active in the dialkylation of naphthalene, for which the parent mordenite did not allow to observe any conversion due to accessibility issues.

When applying a post-synthetic treatment to a zeolite the balance of textural gain vs. chemical loss is of paramount importance. Yet, most of the existing studies take into consideration just a limited amount of parameters. The development of silanol defects, the accessibility to BAS, the impact of the presence of EFAL induced through the treatment, the coherent crystal size (CCS) and lattice strain, among others, are parameters that substantially impact catalytic outputs, which are often neglected when describing the impact of post-synthetic zeolite modifications in catalytic applications. The scope of this contribution is hence to resume the impact of the various postsynthetic modification techniques and compare them as far as texture and chemical property are concerned. Here for a systematic study comparing key properties, such as synthesis yield, coherent crystal size, silanol defects, Brønsted and Lewis acidity, micro- and mesoporosity, $\mathrm{Si} / \mathrm{Al}$ ratio, morphology, has been performed. These have further been correlated to the outputs observed in $n$-hexane cracking and toluene disproportionation, such as initial and final activity, selectivity and coke content.

\section{Results and Discussion}

Eight chemical post-synthetic treatments were carried out on two commercial mordenite zeolites with $\mathrm{Si} / \mathrm{Al}$ ratios of 10 and 20 (denoted $\mathrm{M} 10$ and $\mathrm{M} 20$, respectively). The alkaline treatments were carried out at $85{ }^{\circ} \mathrm{C}$ during $15 \mathrm{~min}$ on M10 and $60 \mathrm{~min}$ on $\mathrm{M} 20$ with different concentration of $\mathrm{NaOH}\left(D^{10}\right.$ and $\left.D^{20}\right)$. The alkaline treatment was further carried out: $I$ ) assisted by microwaves $\left(\mathrm{MW}^{10}\right)$, ii) in the presence of the cationic surfactantcetyltrimethylammonium bromide $\left(\mathrm{CTAB}, \mathrm{DC}^{20}\right)$ and iii) in the presence of pyridine $\left(\mathrm{DP}^{20}\right)$. The fluorine etching was carried out at $25^{\circ} \mathrm{C}$ during $6 \mathrm{~min}$ in: iv) aqueous medium $\left(\mathrm{F}^{10}\right.$ and $\left.\mathrm{F}^{20}\right)$, v) adding ammonium fluoride $\left(\mathrm{NF}^{20}\right)$ or vi) in pyridine medium $\left(\mathrm{PyF}^{10}\right)$. The chemical dealumination was performed at $80-85^{\circ} \mathrm{C}$ during 240 minutes on $\mathrm{M} 10$ by using vii) ammonium hexafluorosilicate $\left(\left(\mathrm{NH}_{4}\right)_{2} \mathrm{SiF}_{6}\right)\left(\mathrm{S}^{10}\right)$ or after viii) the desilication of the parent zeolite in presence of CTAB $\left(D S^{10}\right)$.

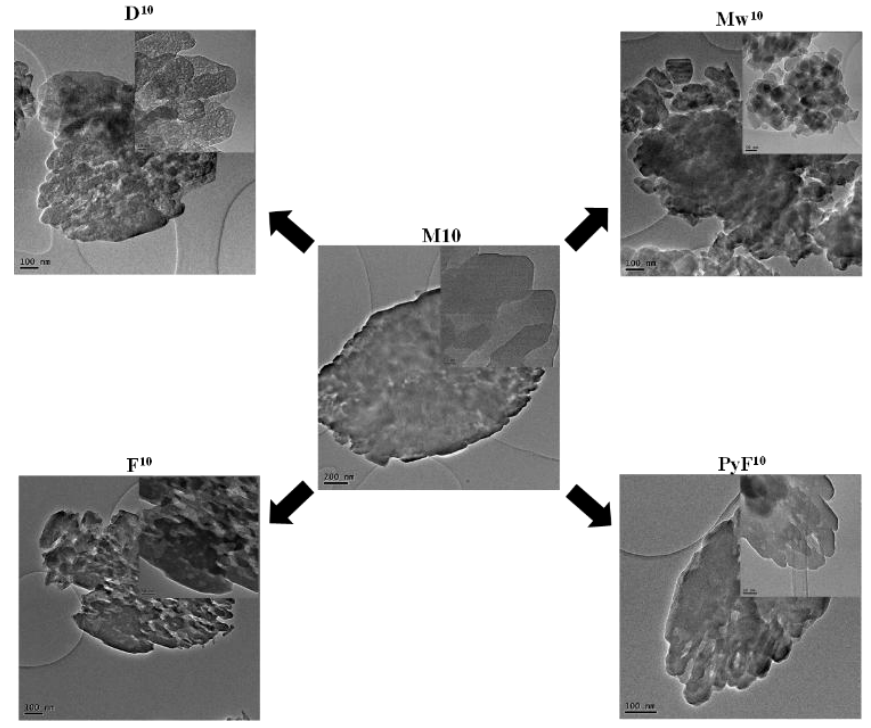

Figure 1. TEM images of parent (M10) and modified mordenites.

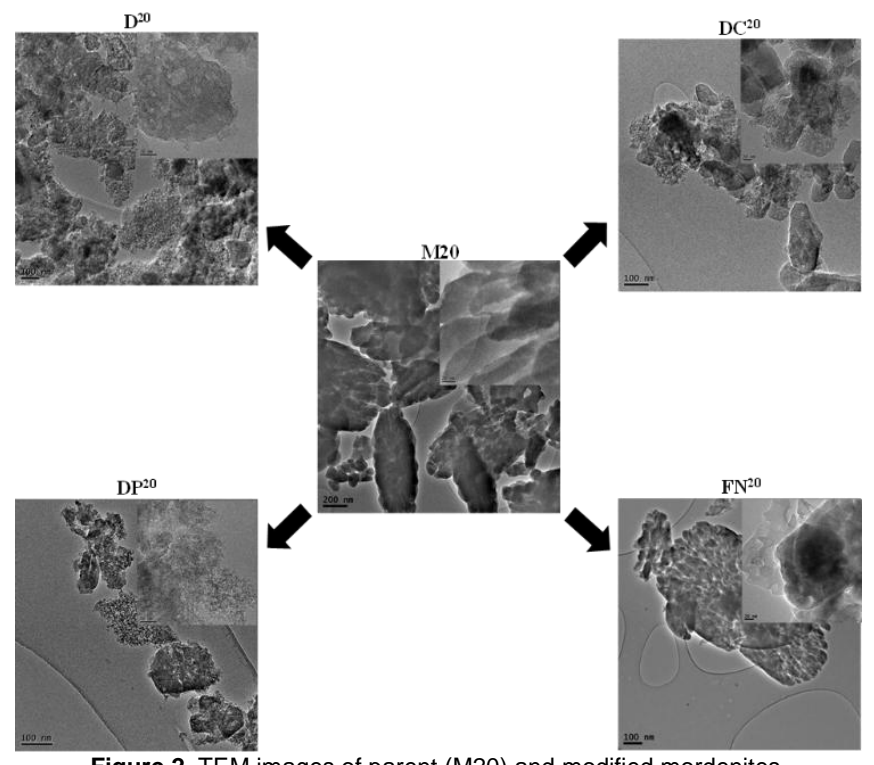

Figure 2. TEM images of parent (M20) and modified mordenites.

\section{Textural properties}

Tables S1 and S2 (see supporting information) summarize the textural properties (microporous and mesoporous volumes, coherent crystal size and strain) and figures 1 and 2 compare the TEM image of the parent mordenites (M10 and M20) and of the eleven catalyst series resulting from the different postsynthetic treatments.

Parent zeolites: Both parent zeolites M10 and M20 present very similar textural properties. They feature type I adsorption and desorption nitrogen isotherms as expected for microporous materials and feature a microporous volume of 0.19 and 0.18 $\mathrm{cm}^{3} \mathrm{~g}^{-1}$, respectively (Figures $\mathrm{S} 1$ and S2, Tables S1 and S2). The morphology of the parent zeolites can be described as aggregates of smaller zeolite particles with sizes comprised between 40 and $100 \mathrm{~nm}$ (Figures 1 and 2). Form WilliamsonHall analysis a coherent crystal size (CCS) of 63 and $66 \mathrm{~nm}$ for $\mathrm{M} 10$ and M20 were calculated with a lattice strain of 8.8 and 7.3, respectively (Tables S1 and S2). 
For further considerations the crystallinity of the parent zeolites has been set as $100 \%$ and the impact of each of the modification strategies has been compared in terms of crystallinity of the obtained samples.

Alkaline treatment: The treatment that most severely impacts microporosity is the alkaline treatment. As expected the basic treatment of the high silica mordenite (M20) affects microporosity more severely than the low silica M10 (Figure 3). The reduction of microporosity correlates well to the reduction of crystallinity (Series $D^{10}$ and $D^{20}$ in tables S1 and S2). Indeed the samples for which microporosity is most impacted present the greatest increase in mesoporous volume (Figure 3). Mesoporous volume substantially develops with increasing concentration of the alkaline solution and amounts to 0.54 and $0.21 \mathrm{~cm}^{3} \mathrm{~g}^{-1}$ for M20 and M10 treated with a $0.6 \mathrm{M} \mathrm{NaOH}$ solution, respectively. From the shape of the nitrogen adsorption and desorption isotherms it can be deduced that the mesoporosity that develops is of rather large size distribution and comprised between 5 and $30 \mathrm{~nm}$ (Figure S1). This was confirmed from the TEM images, which present a rather homogeneous distribution of larger mesoporous (Figures 1 and 2 ). The use of an alternative heating source during alkaline treatment, i.e. microwave heating (Series $\mathrm{Mw}^{10}$ ), does not allow for generating mesoporosity in the same manner as the thermal treatment (Table S1). Indeed, even for the treatment with $0.6 \mathrm{M}$ $\mathrm{NaOH}$ solution the shape of the isotherm is similar to the parent zeolite (Figure S1), yet a more pronounced uptake in the relative pressure range close to saturation can be observed, indicating the creation of interparticular space. This observation is confirmed by the TEM images (Figure 1), which reveal aggregates of particles smaller in size compared to the parent zeolite. Indeed an important reduction in CCS form 63 to $47 \mathrm{~nm}$ was calculated from the FWHM of the XRD peaks for the parent M10 and sample $\mathrm{MW}_{0.6}{ }^{10}$, respectively (Table S1). The addition of pyridine to the desilication solution (Series $\mathrm{DP}^{20}$ ) has substantial impact on the textural features. As such, the crystals are shaped into smaller zeolite particles, which can be inferred from the important nitrogen uptake in the adsorption isotherms at very high relative pressures, which is typical for intraparticular adsorption (Figure S2; Series $\mathrm{DP}^{20}$ ). Indeed, the higher the concentration of pyridine into the alkaline solution the stronger the difference to the classical desilication is observable (Figure S2). The development of smaller zeolite particles can be readily inferred from the TEM images, which presents individual particles of sizes of a few nm (Figure 2). The pyridine assisted desilication is the approach that allows for the strongest modification of textural properties. Indeed adding CTAB during the desilication (Series $\mathrm{DC}^{20}$ ) importantly reduces the amount of developed mesopores, probably through reducing desilication kinetics (Figure 3). For all of the desilication treatments merely little impact on the CCS and the lattice strain was observed (Table S1 and S2). The development of large mesopores only slightly impacts the diffraction efficiency and hence CCS reduction is limited.
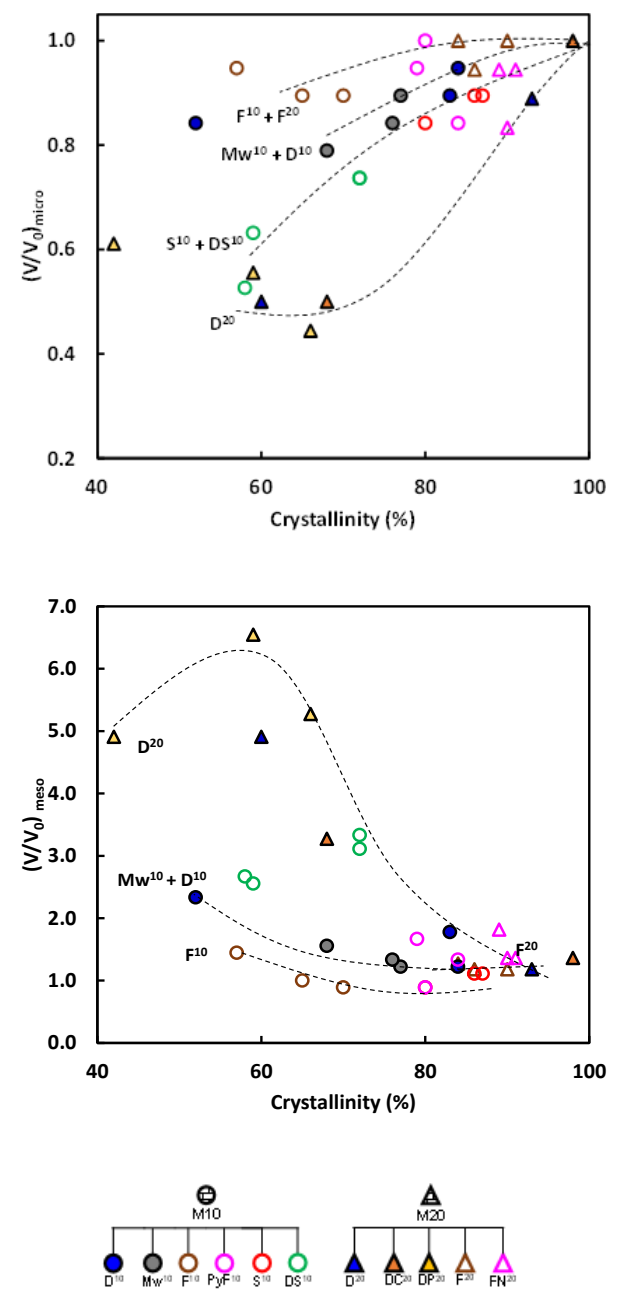

Figure 3. Residual micropore volume and mesopore volume as a function of the crystallinity of the different catalyst series.

HF etching: With contrast to the alkaline treatments, HF etching (Series $\mathrm{F}^{10}$ and $\mathrm{F}^{20}$ ) allows for preserving microporosity to a large extent (Tables S1 and S2). All of the HF treatment procedures lead to the development of very lager intraparticular mesoporosity as indicated through the steep nitrogen uptake in the isotherms recorded at $77 \mathrm{~K}$ (Figures S1 and S2). As far as aqueous HF etching is concerned, it is interesting to note that the $\mathrm{Si} / \mathrm{Al}$ composition of the parent zeolite has a major impact on the CCS and lattice strain. Indeed the treatment with a $0.5 \mathrm{M}$ aqueous HF solution only slightly reduces CCS for M20 whilst it almost halves for M10. This important decrease in CCS is related to the development of internal silanol defects through the treatment as supported by the development of characteristic IR bands (see below). Adding ammonium fluoride to the HF solution (Series $\mathrm{FN}^{20}$ ) only minor impacts textural properties of the mordenite, yet the amount of developed mesoporosity slightly increases. Changing the solvent from water to pyridine importantly impacts the etching path. Indeed for M10, (Series PyF10 in table S1) CCS only reduces slightly, which indicates that the use of pyridine as solvent reduces the amount of internal silanol defects. For all of the samples achieved through HF etching only little textural and morphological changes can be observed through electronic microscopy (Figures 1 and 2).

AHFS treatment: Treating M10 with ammonim hexafluorosilicate hardly impacts textural properties (Series $S^{10}$ 
in table S1). The treatment reduces negligibly microporosity and no mesoporosity is developed. Furthermore the CCS is comparable as that of the parent zeolite.

Summary on textural properties: The choice of the agents used during the post-synthetic treatment of mordenite importantly impact both texture and morphology of the zeolite. Whilst alkaline treatments allow for significantly alter textural properties through the development of intracrystalline mesoporosity and through shaping the zeolite into smaller entities, etching and AHFS treatments have much less impact on texture (Figure 3). The modification of textural properties of zeolite can importantly affect catalytic outputs through e.g. reducing diffusion path length. Yet as we will see below other factors (such as the presence of FEAL species) might even play a more crucial role as far as catalytic activity is concerned.

\section{Acidic properties}

The hydroxyl stretching vibration region of IR spectra before (full line) and after (dashed line) adsorption of pyridine at $150{ }^{\circ} \mathrm{C}$ on the eleven catalyst series are given in figures 4 and 5 . The tables S3 and S4 report the global Si/Al ratio and the concentration of Brønsted and Lewis acid sites probed by pyridine at $150^{\circ} \mathrm{C}$ for each sample.

Parent zeolites: M10 presents in figure 3 a high intense band centered at $3608 \mathrm{~cm}^{-1}$, which is related to the bridged hydroxyl groups and three less intensed bands at 3745,3733 and 3684 $\mathrm{cm}^{-1}$, which can be attributed to the stretching vibrations of external and internal silanol groups and hydroxyl groups related to extraframework aluminium species (EFAL), respectively. M20 presents these four bands and an additional one at $3503 \mathrm{~cm}^{-1}$, which is ascribable to the presence of hydroxyl nests and is due to its preparation process (dealumination), (Figure 4). Contrary to M20, not all the bridged hydroxyl groups are neutralized after the adsorption of pyridine at $150^{\circ} \mathrm{C}$ on $\mathrm{M} 10$, which means that part of the Brønsted acid sites (BAS) are inaccessible to the probe molecule. These inaccessible BAS are located in the side pockets and amount to $19 \%$, as calculated by six bands deconvolution in our previuos study. ${ }^{[17]}$

Alkaline treatments: The alkaline treatment by both thermal or microwave heating leads to an important decrease of the $\mathrm{Si} / \mathrm{Al}$ ratio (7.5-6.3), which is more important for samples treated with increasing $\mathrm{NaOH}$ concentration (Table S3). The common alkaline treatment on $M 10\left(D^{10}\right.$ series) leads to a decrease of the intensity of the band at $3606 \mathrm{~cm}^{-1}$ (decreasing accessibility of pyridine to the bridged $\mathrm{OH}$ ), yet without significant modification of the silanol bands (Figure 4).

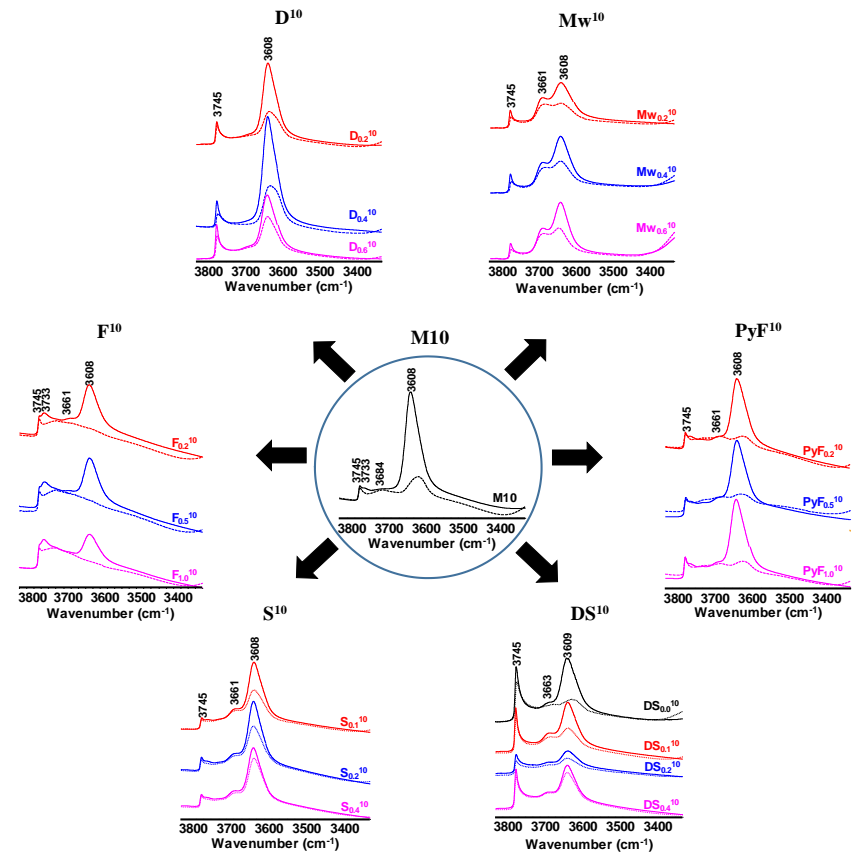

Figure 4. Comparison of IR spectra before and after pyridine adsorption at $150{ }^{\circ} \mathrm{C}$ of M10 and the six catalyst series.

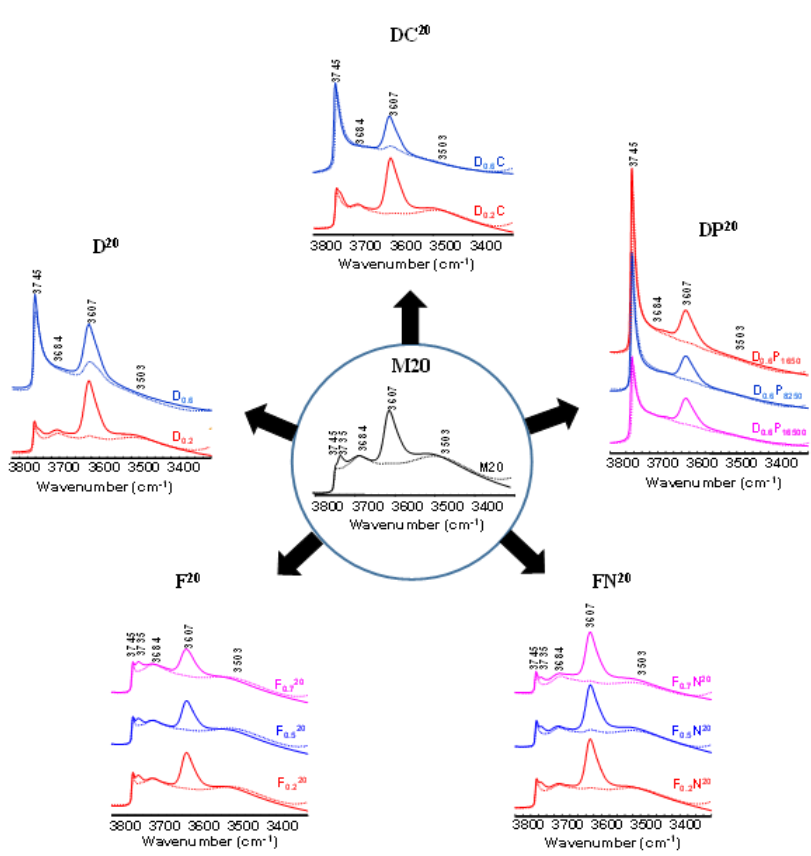

Figure 5. Comparison of IR spectra before and after pyridine adsorption at $150^{\circ} \mathrm{C}$ of M20 and the six catalyst series.

On $\mathrm{M} 10$ treated with a high concentration of $\mathrm{NaOH}(0.6 \mathrm{M}$, $\left.\mathrm{D}_{0.6}{ }^{10}\right)$, less than $40 \%$ of bridged $\mathrm{OH}$ band are neutralized by the organic probe (Table S3), which indicates an important accumulation of extra framework silicon and aluminium specie in the large channels of mordenite zeolite. The losses of the bridged $\mathrm{OH}$ and of their accessibility, yield to a significant decrease in the number of BAS, e.g. on $\mathrm{D}_{0.6}{ }^{10}$ sample, the remaining concentration after alkaline treatment is only the quarter of the parent zeolite (Table S3). It is worth to mention that in this study no subsequent acid leaching was performed, which would allow to remove such EFAL species. When the alkaline treatment is assisted by microwave heating $\left(\mathrm{Mw}^{10}\right.$ series), many hydroxylated EFAL specie (band at $3661 \mathrm{~cm}^{-1}$ ) 
develop independently of the $\mathrm{NaOH}$ concentration. These species lead to an increased inaccessibility of pyridine to BAS located within the zeolite micropores. Indeed, the alkaline treatment assisted by microwave heating promotes both the dislodgement of aluminium and silicon from the zeolite framework and yields to a large amount of hydroxylaluminates (e.g. $\left.\mathrm{Al}(\mathrm{OH})^{2+}, \mathrm{Al}(\mathrm{OH})^{+}{ }_{2}, \mathrm{AlOOH}, \mathrm{Al}(\mathrm{OH})_{3}\right)^{\text {). }}{ }^{[25,26]}$

On M20, the presence of pyridine and CTAB in solution during the basic treatment prevents even at high $\mathrm{NaOH}$ concentration $(0.6 \mathrm{M})$ the desilication of the framework (Table S4). The impact of alkaline treatment carried out with a low concentration of sodium hydroxide $(0.2 \mathrm{M})$ is limited. While with $0.6 \mathrm{M}$, although the bridged $\mathrm{OH}$ are in large part preserved (unlike on M10), hydroxyl nests (band at $3503 \mathrm{~cm}^{-1}$ ) are removed and the formation of external silanol (band at $3745 \mathrm{~cm}^{-1}$ ), especially when desilication occurs in presence of pyridine, is favored (Figure 5). Moreover the presence of pyridine allows preserving the accessibility to the BAS.

HF etching: Fluorine etching on $\mathrm{M} 10$ and $\mathrm{M} 20\left(\mathrm{~F}^{10}\right.$ and $\mathrm{F}^{20}$ series) only impacts the intensity of the band related to the framework aluminium species (band at $3608 \mathrm{~cm}^{-1}$, Figures 4 and 5). The higher the employed HF concentration, the lower the intensity of the bridging $\mathrm{OH}$ band and the higher the obtained $\mathrm{Si} / \mathrm{Al}$ ratio (Tables S3 and S4). The dealumination with HF leads, as expected, to the reduction of the concentration of Brønsted acid sites (Tables S3 and S4) and concomitantly with the appearance of the non-hydroxylated Lewis acid sites (such as $\mathrm{Al}_{2} \mathrm{O}_{3}$ ). Assuming that the Lewis species are constituted of two aluminum atoms, the global acidity probed by pyridine $\left(\left[\mathrm{PyH}^{+}\right]\right.$ $+2[\mathrm{PyL}])$ is close to the amount measured on the parent zeolites. The addition of ammonium ions, i.e. $\mathrm{NH}_{4}^{+}$for $\mathrm{FN}^{20}$ and pyridinium ions for $\mathrm{PyF}^{10}$, leads to an unbiased treatment, ${ }^{[17]}$ thus preserving a large part of the acidic properties of the parent zeolites.

AHFS treatment: The chemical dealumination with ammonium hexafluorosilicate on $\mathrm{M} 10 \quad\left(\mathrm{~S}^{10}\right.$ series) leads to a slight dealumination as indicated by the low increase of $\mathrm{Si} / \mathrm{Al}$ ratio (Table S3). The intensity of the bridged $\mathrm{OH}$ but especially their accessibility decreases with increasing concentration of hexafluorosilicate ion used during the treatment (Figure 4). Only $20 \%$ of BAS are accessible to pyridine on $\mathrm{S}_{0.4}{ }^{10}$ against $80 \%$ on the parent zeolite (Table S3). The presence of the band at 3661 $\mathrm{cm}^{-1}$ (which is related to the hydroxylated extraframework aluminium species) confirms the occurrence of dealumination. The loss of acid site accessibility is due to the deposition of EFAL specie and formation of silicon specie that block the micropore aperture. Washing of treated material with hot water is not sufficient to remove/dissolve these trapped species. Even the presence of intracrystalline mesopores (DS ${ }^{10}$ series) does not allow to preserve the accessibility of acidic sites. Hence, the most appropriate method would be to perform a subsequent mild acid leaching, which is known to remove such extraframework species.

Summary on acidic properties: The relative increase or decrease of the Si/Al molar ratio resulting from the various posttreatments is plotted as a function of crystallinity (Figure 6). After alkaline treatment, the final/initial Si/Al ratio is independent of the achieved crystallinity (even for the sample for which less than $50 \%$ crystallinity was preserved) and is 0.9 and 0.7 for M10 and $\mathrm{M} 20$, respectively. While after dealumination treatments, crystallinity decreases concomitantly with increasing $\mathrm{Si} / \mathrm{Al}$ ratio, especially for samples in which M10 was used as parent zeolite. The dislodgement of several aluminum contrary to that of silicon atoms leads to a local collapse of the zeolite framework.
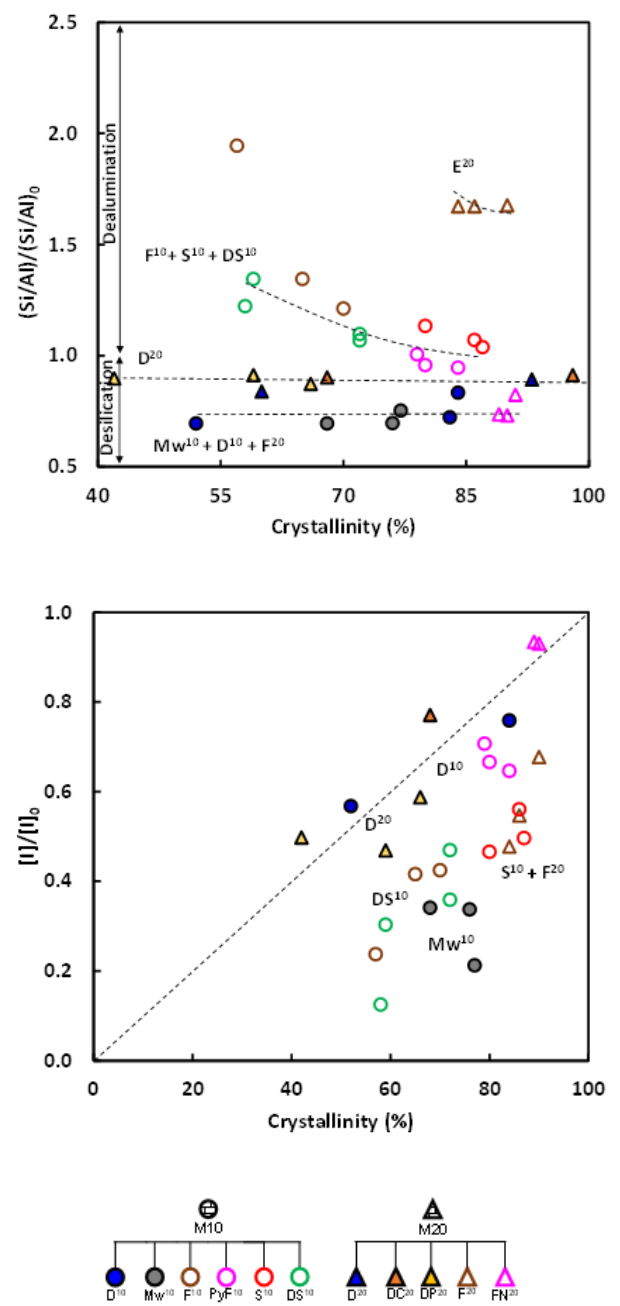

Figure 6. Normalization of $\mathrm{Si} / \mathrm{Al}$ molar ratio and intensity of the bridged hydroxyl IR band $\left(3608 \mathrm{~cm}^{-1}\right)$ as a function of the crystallinity.

Figure 6 shows the relative intensity $\left(1 / /_{0}\right)$ of the bridged $\mathrm{OH}$ band as a function of crystallinity. The use of $1 / \mathrm{I}_{0}$ unlike that of the residual Brønsted acidity ([BAS]/[BAS], Figure S3) makes it possible to avoid the accessibility issue. The relative intensity of the bridged $\mathrm{OH}$ band is proportional to the crystallinity of the zeolites modified by alkaline treatment, with the exception of those obtained by microwave heating ( $\mathrm{Mw}^{10}$ series). Concerning the dealuminated zeolites, as expected the ratio of intensities $\left(\mathrm{I} / \mathrm{I}_{0}\right)$ decreases more rapidly than the crystallinity, the loss of the acidity is mainly due to the dealumination and to a lesser extent to the decrease of the crystallinity. In addition, the alkaline treatment assisted by microwave heating leads to an unbiased dealumination and desilication of the zeolite framework.

\section{Catalytic properties}

The acid properties of achieved catalysts are characterized by $n$ hexane cracking ( $\alpha$ test) and toluene disproportionation. ${ }^{[27]}$ No change of the mechanisms were observed, despite the different textural and acidic properties of catalysts. Cracking products are formed in strictly parallel reactions, which indicate a monomolecular mechanism (Figure S4a) and toluene 
disproportionation yields mixture of benzene and xylenes with the same selectivity at isoconversion (Figure S4b). Figure 7 compares for all achieved catalysts the initial activity $\left(A_{0}\right)$ and coke contents $(\% \mathrm{C})$ as a function of the concentration of Brønsted acid sites. Regarding to $n$-hexane cracking, no obvious correlation appears between acidity and initial activity or the coke deposition.

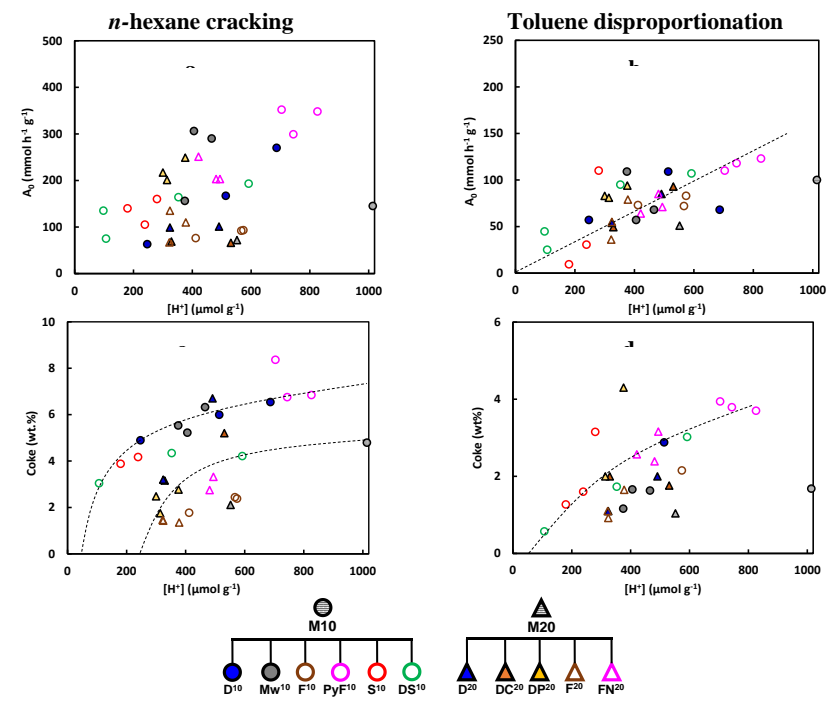

Figure 7. $n$-Hexane cracking at $541^{\circ} \mathrm{C}$ and toluene disproportionation at $450{ }^{\circ} \mathrm{C}$ on achieved catalysts: initial activity (top) and coke content after $1 \mathrm{~h}$ of reaction (bottom) as a function of the concentration of the Brønsted acid sites probed by pyridine.

This indicates that the formation of coke mainly depends on the origin of the parent zeolite and to a less important extent on the concentration of acid sites, which however is not consistent with the mechanism of coke formation. ${ }^{[28]}$ As far as the toluene transformation is concerned, the initial activity and the coke content show to increase proportionally with BAS.

The absence of the expected tendency in $n$-hexane cracking can be ascribed to the fact that only the number of BAS probed by pyridine were taken into consideration and not the actual number of active sites. While toluene and pyridine feature a similar kinetic diameter, i.e. 6.0 and $5.7 \AA$, respectively, the kinetic diameter $n$-hexane is lower $(4.3 \AA)$. The number of active sites encountered by $n$-hexane must therefore be higher. Accordingly, we assume that all bridged hydroxyl groups are accessible to $n$-hexane. The acidic sites concentration is thus corrected by the degree of accessibility derived from the IR study.

$$
\left[\mathrm{H}^{+}\right]_{\text {CORRECTED }}=\frac{\left[\mathrm{H}^{+}\right]_{\text {probed by pyridine }}}{\text { accessibility degree }}
$$

By applying this correction, we observe that the coke content increases with increasing concentration of acid sites and is higher on desilicated catalysts (i.e $. \mathrm{D}^{10}, \mathrm{D}^{20}, \mathrm{DC}^{20}, \mathrm{Mw}^{10}$ ) and on the $\mathrm{PyF}^{10}$ series (Figure 8). This is consistent with what was previously reported, as desilicated catalyst promotes the coke retention. ${ }^{[25,27,29]}$ The initial cracking activity is now proportional to concentration of the acid sites after having taken into account their accessibility, except for $\mathrm{DP}^{20}, \mathrm{FN}^{20}, \mathrm{PyF}^{10}$ and $\mathrm{Mw}^{10}$. The more important activity of these catalyst series could be ascribed to an exaltation of BAS by EFAL species generated during the calcination of the zeolite containing ammonium or pyridinium ions or during microwave heating. ${ }^{[17,30,31]}$
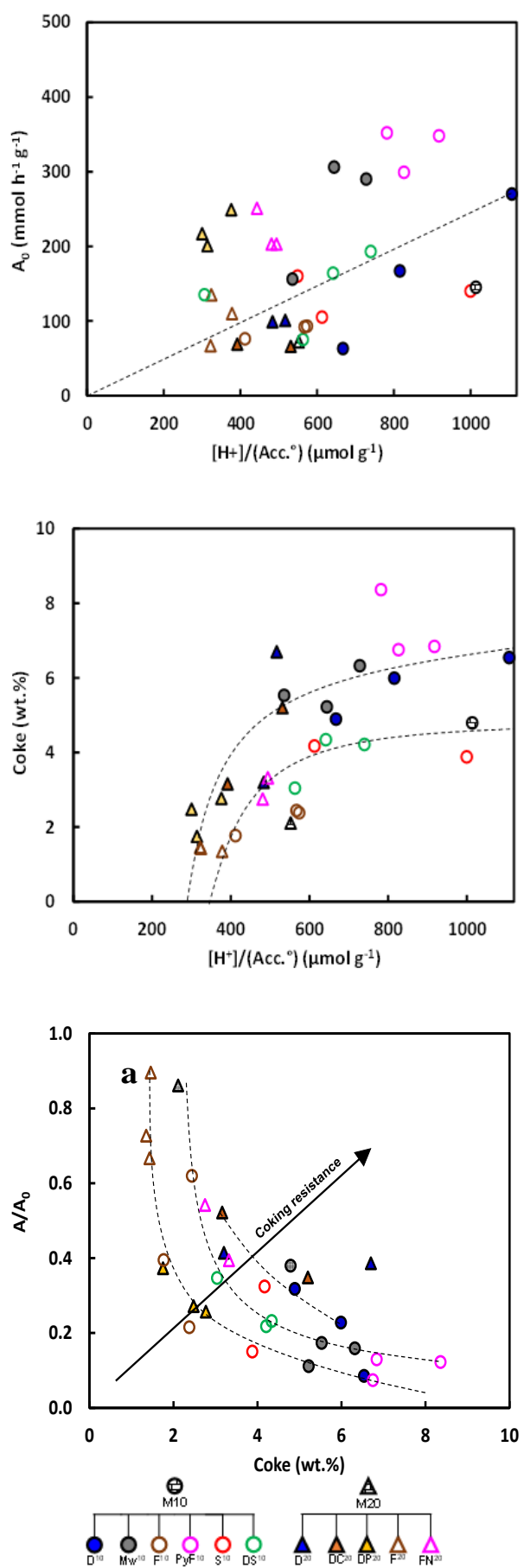

Figure 8. Initial cracking activity and coke content as a function of the concentration of the actual accessible Brønsted acid sites. 

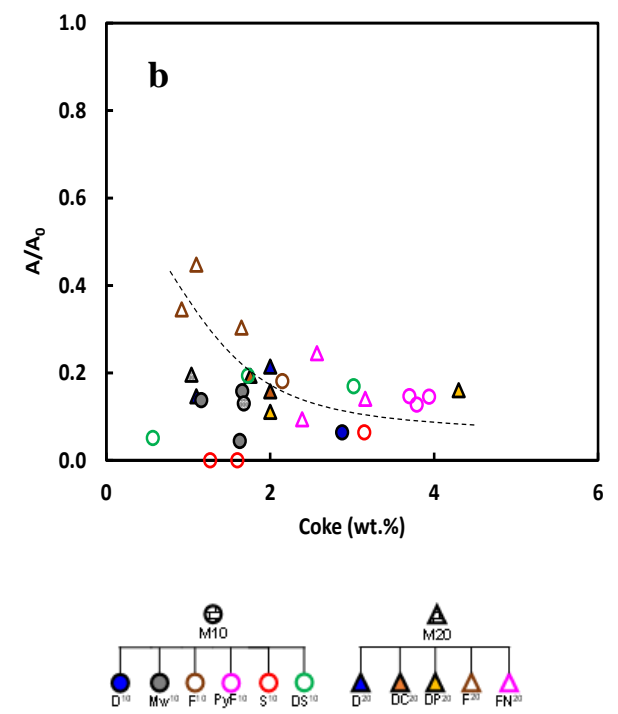

Figure 9. Residual activity after 1 hour reaction of $n$-hexane cracking (a) and toluene disproportionation (b) a as a function coke content.

Figure 9 reports the residual activity $\left(\mathrm{A} / \mathrm{A}_{0}\right)$ after 1 hour of $n$ hexane cracking and toluene disproportionation as a function of the coke content. For both reactions, $\mathrm{A} / \mathrm{A}_{0}$ decreases rapidly with increasing coke content. On the mordenite zeolite, a low coke content is already sufficient to block the access to all the acidic sites located within a given 12-MR channel. ${ }^{[28]}$ In the toluene disproportionation, the coke toxicity is independent of the applied treatment, whereas for the $n$-hexane cracking different catalyst series can be lumped together according to their tolerance to coking. As such we observe that the most coke resistant catalysts are those achieved through desilication $\left(D^{10}\right.$, $\mathrm{D}^{20}$ and $\mathrm{DC}^{20}$ series), followed by $\mathrm{FN}^{20}$ and $\mathrm{PyF}^{10}$ catalysts. Finally the most sensitive catalysts to coking are those prepared through etching $\mathrm{F}^{10}, \mathrm{~F}^{20}$ and $\mathrm{DP}^{20}$.

\section{Summary and outlook}

The quest to impact textural properties of mordenites has allowed for developing a large plethora of post synthetic techniques. Table 1 gives an overview of the impact of the different post-synthetic mordenite modification strategies that have been investigated on textural, acidic and catalytic properties. None of the described treatments allows to completely preserve Brønsted acidity of the parent zeolites, as the reduction of BAS is due to the reduction of crystallinity. The strongest reduction of BAS is observed for alkaline treatments, which generate an important amount of external silanol defects. Yet, desilication is the method of choice for the development of intracrystalline mesoporosity. It is the generation of mesoporosity that allows for observing improved resistance to coking, by promoting the desorption of coke precursors, through a reduction of the diffusion path length. Yet, this does not allow to achieve higher catalytic activities. Indeed, the catalysts that allow for increasing catalytic outputs are those in which extraframework species are present and which exalt the strength of the Brønsted acid sites and increase confinement. The best strategy in terms of catalyst activity (which de facto includes the preservation of acidity) is the fluorine etching in presence of pyridine.

\section{Experimental Section}

\section{Materials}

Alkaline treatments, chemical dealumination and fluorine etching were carried out on protonic mordenite zeolites (Süd Chemie) with Si/Al ratio of 10 and 20 (noted M10 and M20). The operating conditions used and obtained yield are summarized in the tables S5 and S6.

Alkaline treatment: Classical alkaline treatment $\left(D^{10}\right.$ and $D^{20}$ series) was performed by treating $1 \mathrm{~g}$ of zeolite with $15 \mathrm{~mL}$ of aqueous $\mathrm{NaOH}$ solution $(0.2-0.6 \mathrm{M})$ at $85^{\circ} \mathrm{C}$ for $60 \mathrm{~min}$ and $15 \mathrm{~min}$ for $\mathrm{M} 20$ and $\mathrm{M} 10$ respectively, under stirring $(400 \mathrm{rpm})$. The catalysts were recovered by centrifugation, washed with deionized water, dried and calcined at $550{ }^{\circ} \mathrm{C}$ for $4 \mathrm{~h}$ (heating rate $5^{\circ} \mathrm{C} \mathrm{min}^{-1}$ ). The protonic form of the catalyst were obtained after three consecutive exchange cycles with a $1 \mathrm{M}$ solution of $\mathrm{NH}_{4} \mathrm{NO}_{3}$ using $50 \mathrm{~cm}^{3} \mathrm{~g}^{-1}$. The exchange was carried out at $85^{\circ} \mathrm{C}$ for $1 \mathrm{~h}$. After careful washing to $\mathrm{pH} 7$ the solids were dried at $80^{\circ} \mathrm{C}$ during $12 \mathrm{~h}$ and then calcined $550{ }^{\circ} \mathrm{C}$ for $4 \mathrm{~h}$. CTAB assisted alkaline treatment $\left(D^{20}\right.$ series): Analogous to the classical alkaline treatment hexadecyltrimethylammonium bromide (CTAB, $0.27 \mathrm{M}$ ) was added to the alkaline solution prior to the addition of M20. Pyridine assisted alkaline treatment $\left(\mathrm{DP}^{20}\right)$ : Analogous to the classical alkaline treatment, pyridine was added to the alkaline solution prior to the addition of the zeolite. The amount of pyridine added to the alkaline solution were 1650, 8250 and $16500 \mu \mathrm{mol} \mathrm{g}^{-1}$, which correspond to ca 3, 15 and 30 times the number of Brønsted acid sites probed on M20 by pyridine at $150{ }^{\circ} \mathrm{C}$. Alkaline treatment using microwaves $\left(\mathrm{MW}^{10}\right)$ : Classical dealumination on $\mathrm{M} 10$ was carried out in Teflon crucible that where heated in a microwave (Microsynth, Milestone) using an input power of $250 \mathrm{~W}$ for $15 \mathrm{~min}$.

Table 1. Overview on post-synthetic mordenite modification strategies: Impact on textural, acidic and catalytic properties.

\begin{tabular}{|c|c|c|c|c|c|c|c|c|c|c|c|}
\hline \multirow{3}{*}{$\begin{array}{l}\text { Treatment } \\
\text { series } \\
\text { Si/Al }\end{array}$} & \multicolumn{5}{|c|}{ Alkaline treatment } & \multicolumn{4}{|c|}{ Acid etching } & \multicolumn{2}{|c|}{$\begin{array}{c}\text { Chemical } \\
\text { dealumination }\end{array}$} \\
\hline & & & MW & DC & DP & & & FN & PyF & $\mathbf{S}$ & DS \\
\hline & 10 & 20 & 10 & 20 & 20 & 10 & 20 & 20 & 10 & 10 & 10 \\
\hline Yield & $=-$ & - & $=$ & -- & -- & $=-$ & -- & - & -- & & $=$ \\
\hline Crystallinity & -- & -- & $=$ & - & --- & -- & - & & $=$ & - & -- \\
\hline CSS & - & & -- & -- & - & $=--$ & -- & - & & & - \\
\hline Strain & + & + & ++ & ++ & + & +++ & +++ & + & & & ++ \\
\hline
\end{tabular}




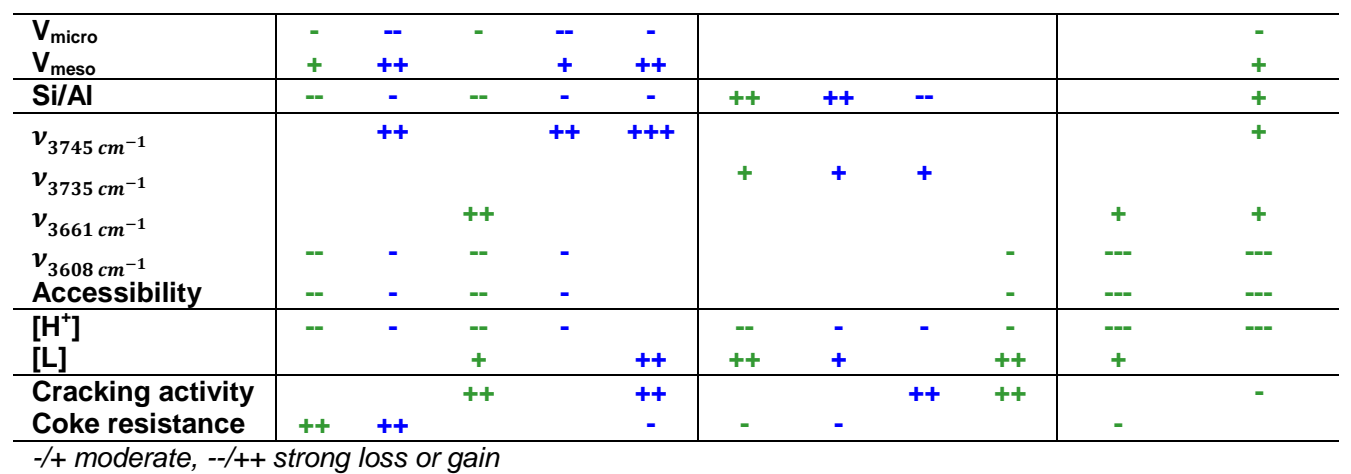

$H F$ etching was carried out through the use of an aqueous HF solution $\left(\mathrm{F}^{10}, \mathrm{~F}^{20}\right)$ or ammonium fluoride $(4.5 \mathrm{M})$ on $\mathrm{M} 20\left(\mathrm{FN}^{20}\right)$ and a solution of $\mathrm{HF}$ in pyridine on $\mathrm{M} 10\left(\mathrm{PyF}^{10}\right)$. In a $100 \mathrm{~mL}$ Teflon vessel were placed 1 $\mathrm{g}$ of the parent mordenite. $20 \mathrm{~mL}$ of the $\mathrm{HF}$ solution of different concentrations ranging from 0.2 and and $1.50 \mathrm{M}$ was added at $25^{\circ} \mathrm{C}$ for 6 min unde

$r$ mechanical stirring (500 rpm). Thereafter the zeolite suspensions were centrifuged at $6000 \mathrm{rpm}$ for $10 \mathrm{~min}$. The residue was washed with $40 \mathrm{~mL}$ demineralized water. Washing cycles were performed until neutral $\mathrm{pH}$. Solids were dried at $100{ }^{\circ} \mathrm{C}$ for $12 \mathrm{~h}$ and calcined under air flow $(100 \mathrm{ml}$ $\min ^{-1}$ per $1 \mathrm{~g}$ of zeolite) at $550{ }^{\circ} \mathrm{C}$ for $8 \mathrm{~h}$.

Ammonium hexafluorosilicate (AHFS) treatment: $1 \mathrm{~g}$ of $\mathrm{NH}_{4}-\mathrm{MOR}$ was preheated at $80^{\circ} \mathrm{C}$ in a $50 \mathrm{~mL}$ of $3 \mathrm{M}$ aqueous solution of $\mathrm{NH}_{4} \mathrm{OAc}$. Then $10 \mathrm{~cm}^{3}$ of $0.1 \mathrm{M}$ aqueous AHFS solution was added drop-wise during $1 \mathrm{~h}$. The solution was then kept at $80^{\circ} \mathrm{C}$ with constant stirring (400 rpm) for 3 $\mathrm{h}$. The resulting solution was recovered by filtration and repeatedly washed with $1 \mathrm{~L}$ of hot water $\left(80^{\circ} \mathrm{C}\right)$. After that, the material was dried for $12 \mathrm{~h}$ at $100{ }^{\circ} \mathrm{C}$ followed by calcination at $650^{\circ} \mathrm{C}$ for $4 \mathrm{~h}$.

\section{Characterization techniques}

X-ray diffraction patterns of the zeolites were obtained using D5005 BRUKER AXS diffractometer with $\mathrm{CuK}_{\alpha}$ radiation $(\lambda=1.541874 \AA)$. The scan range was from $5^{\circ}$ to $50^{\circ} 2 \theta$. The relative crystallinity was estimated by comparing the diffraction line intensities of the modified mordenites with that of the parent ones. The Willamson-Hall relation was used to calculate the coherent crystallite size (CCS) and lattice strain (S).[24] The texture and morphology of the parent and treated samples was evaluated using Philips CM 120 transmission electron microscopy (TEM), equipped with a $\mathrm{LaB}_{6}$ filament. Nitrogen physiosorption measurements were performed in liquid-nitrogen $\left(-196^{\circ} \mathrm{C}\right)$ using a Micromeritics 3FLEX apparatus. Prior any measurement, $50-60 \mathrm{mg}$ of the sample was vacuum-degassed at $350{ }^{\circ} \mathrm{C}$ for $12 \mathrm{~h}$. The micropore volume was calculated by $t$-plot method and the $\mathrm{N}_{2}$ adsorbed volume at $\mathrm{p} / \mathrm{p}_{0}=0.96$ was used to estimate the total pore volume. The chemical compositions were measured using Perkin Elmer Optima 2000 DV Inductively Coupled Plasma-Atomic Emission Spectroscopy (ICP -AES). OH-spectra and Pyspectra were recorded using a Nicolet 5700 spectrometer, with $2 \mathrm{~cm}^{-1}$ optical resolution, in the range $3800-3300 \mathrm{~cm}^{-1}$ and $1700-1300 \mathrm{~cm}^{-1}$, respectively. Prior to the measurement, $10-30 \mathrm{mg}$ of the catalyst powder was pressed into a self-supporting wafer $\left(2 \mathrm{~cm}^{2}\right)$, pretreated in the IR-cell at $450{ }^{\circ} \mathrm{C}$ for $12 \mathrm{~h}$ under air flow $\left(60 \mathrm{~cm}^{3} \mathrm{~min}^{-1}\right)$ and then degassed at $200{ }^{\circ} \mathrm{C}$ during $1 \mathrm{~h}$, after which the $\mathrm{OH}-\mathrm{IR}$ spectrum was taken. After that, the sample was cooled to $150{ }^{\circ} \mathrm{C}$ and the pyridine $(1.5 \mathrm{mbar})$ was injected for $5 \mathrm{~min}$, followed by an outgassing step at $10^{-5}$ bar in order to eliminate the physisorbed pyridine. The Brønsted and Lewis acidities were calculated on the basis of the absorbance observed at 1545 and $1454 \mathrm{~cm}^{-1}$, respectively and using the following extinction coefficients measured at $293 \mathrm{~K}: \varepsilon_{1545}=1.13$ and $\varepsilon_{1454}=1.28 \mathrm{~cm} \mathrm{~mol}^{-1}$.

Catalyst activity was evaluated by $n$-hexane cracking and toluene disproportionation using tubular glass fixed-bed microreactors under plug flow conditions. The zeolites were pressed, crushed and sieved into 0.2-
$0.4 \mathrm{~mm}$ particles. Before to the cracking reaction, the catalysts were pretreated at $540{ }^{\circ} \mathrm{C}$ in nitrogen flow of $100 \mathrm{~mL} \mathrm{~min}^{-1}$ for $8 \mathrm{~h}$. For the disproportionation reaction the pretreated temperature was $450{ }^{\circ} \mathrm{C}$. Hexane introduced to the reactor at the same temperature and nitrogen flow $\left(0.1 \mathrm{MPa}, \mathrm{N}_{2} / \mathrm{n}-\mathrm{C}_{6}=9\right)$ and the contact time was fixed at $0.04 \mathrm{~s}$. When the temperature reduced to $420{ }^{\circ} \mathrm{C}$, toluene was injected by the hydrogen flow $\left(0.1 \mathrm{MPa}, \mathrm{H}_{2} / \mathrm{n}-\mathrm{C}_{7}=4\right)$ and the contact time was fixed at $0.12 \mathrm{~s}$.

Reaction products were sampled in a 10-port valve during $1 \mathrm{~h}$, then analyzed online by gas chromatographs (GC) equipped with Flame Ionization Detector (FID). A $50 \mathrm{~m} \mathrm{Cp}-\mathrm{Al}_{2} \mathrm{O}_{3} / \mathrm{Na}_{2} \mathrm{SO}_{4}$ capillary column of $0.32 \mathrm{~mm}$ internal diameter was used for cracking process, while a $60 \mathrm{~m}$ $\mathrm{BR}$ wax column of $0.25 \mathrm{~mm}$ internal diameter was used for the disproportionation.

\section{Acknowledgements}

Hussein Issa thanks Islamic Center Association for guidance and higher education for the financial support of his doctoral studies. The authors acknowledge financial support from the European Union (ERDF) and "Région Nouvelle Aquitaine".

Keywords: zeolite $\cdot$ mordenite $\cdot$ hierarchical $\cdot$ n-hexane cracking toluene disproportionation

[1] K. Tanabe, W. F. Hölderich, Appl. Catal. A 1999, 181, 399-434

[2] D. Lei, B. T. Carvill, W. M. H. Sachtler, Appl. Catal. 1996, 42 347-359.

[3] P. Magnoux, P. Cartraud, S. Mignard, M. Guisnet, J. Catal. 1987, 106 242-250.

[4] M. S. Holm, E. Taarning, K. Egeblad, C. H. Christensen, Catal. Today 2011, 168, 3-16.

[5] A. Sachse, J. Garcia Martinez, Chem. Mater. 2017, 29, 3827-3853.

[6] H. Sammoury, J. Toufaily, K. Cherry, T. Hamieh, Y. Pouilloux, L. Pinard, Appl. Catal. Gen. A. 2018, 551, 1-12.

[7] L. Y. Jia, M. Raad, S. Hamieh, J. Toufaily, T. Hamieh, M. M. Battahar, G. Mauviel, M. Tarrighi, L. Pinard, A. Dufour, Green Chem. 2017, 22, $1-19$.

[8] X. Li, R. Prins, J. A. van Bokhoven, J. Catal. 2009, 262, 257-265.

[9] G. S. J. Lee, J. M. Garces, G. R. Meima, M. J. M. van der Aalst, , WO Patent 000317 (1993)

[10] M. Boveri, C. M.-Álvarez, M. Á. Laborde, E. Sastre, Catal. Today 2006 $114,217-225$

[11] H. -M. Kao, Y. -C. Chen, C. -C. Ting, P. T. Chen, J. -C. Jiang, Catal. Today 2004, 97, 13-23.

[12] Q. L. Wang, M. Torrealba, G. Giannetto, M. Guisnet, G. Perot, M Cahoreau, J. Caisso, Zeolites 1990, 10, 703-706.

[13] G. Garralon, V. Fornes, A. Corma, Zeolites 1988, 8, 268-272.

[14] J. M. Silva, M. F. Riberio, F. R. Ribeiro, E. Benazzi, N. S. Gnep, M. Guisnet, Zeolites 1996, 16, 275-280.

[15] A. K. Ghosh, R. A. Kydd, J. Catal. 1987, 103, 399-406. 
[16] Z. Qin, L. Lakiss, J. -P. Gilson, K. Thomas, J. -M. Goupil, C. Fernandez, V. Valtchev, Chem. Mater. 2013, 25, 2759-2766.

[17] H. Issa, J. Toufaily, T. Hamieh, J. -D. Comparot, A. Sachse, L. Pinard, J. Catal. 2019, just accepted

[18] J. C. Groen , T. Sano , J. A. Moulijn, J. Pérez-Ramírez, J. Catal. 2007, 251, 21-27.

[19] S. Abello, J. Perez-Ramirez, Phys. Chem. Chem. Phys. 2009, 11, 2959-2963.

[20] SV. Piaxao, R. Monteiro, M. Andrade, A. Fernandes, J. Rocha, A. P. Carvalho, A. Martins, Appl. Catal. Gen. A. 2011, 402, 59-68.

[21] I. I. Ivanova, E. E. Knyazeva, Chem. Soc. Rev. 2013, 42, 3671-3688.

[22] I. Ivanova, I. A. Kasyanov, A. A. Maerle, V. I. Zaikovskii, Micro. Meso. Mater. 2013, 189, 163-172.

[23] A. Kasyanov, A. Maerle, I. I. Ivanova, J. Mater. Chem. A 2014, 2 , 16978-16988.

[24] D. Mote, Y. Purushotham, B. N. Dole, J. Theor. Appl. Phys. 2012, 6, 614.

[25] VM. -C Silaghi, C. Chizallet, P. Raybaud, Micro. Meso. Mater. 2014 191, 82-96
[26] D. L. Bhering, A. Ramirez-Solis, C. J. A. Mota, J. Phys. Chem. B 2003 107, 4342-4347

[27] M. Guisnet, L. Pinard, Catal. Rev. 2018, 60, 337-436.

[28] N. Chaouati, A. Soualah, M. Chater, L. Pinard, J. Catal. 2017, 353, 28 36.

[30] F. Ngoye, L. Lakiss, Z. Qin, S. Laforge, C. Canaff, M. Tarighi, V. Valtchev, K. Thomas, A. Vicente, J. -P. Gilson, Y. Pouilloux, C Fernandez, L. Pinard, J. Catal. 2014, 320, 118-126.

[31] P. Ratnasamy, S. Sivankar, A. Vishnoi, J. Catal. 1981, 69, 428-433.

[32] I. Bankos, A. L. Klyachko, T. R. Brueva, G. I. Kapustin, Reat. Kinet Catal. Lett. 1986, 30, 297-302

[33] H. Wei, S. Xie, N. Gao, K. Liu, X. Liu, W. Xin, X. Li, S. Liu, L. Xu, App. Catal. Gen. A 2015, 495, 152-161.

[34] H. Issa, J. Toufaily, T. Hamieh, A. Sachse, L. Pinard, Appl.Catal. Gen A 2019 submitted. 
